\title{
Improved automated technique for the estimation of iron in ferrioxamine
}

\author{
A. K. SINGH \\ From the Department of Haematology, St. Thomas's Hospital and Medical School, London
}

SYNOPSIS A modified automated technique for the estimation of iron in the ferrioxamine complex is described. The use of sodium dithionite as the reducing agent gave greater recovery from ferrioxamine-containing solutions when compared with a standard manual method and automated method currently used. In addition errors due to urinary pigments are eliminated by dialysis.

Available methods for the determination of serum iron appeared inadequate for the measurement of urinary iron, particularly when chelated with desferrioxamine. A simple technique using a Technicon AutoAnalyzer is described and the results compared with two other established methods.

\section{METHOD}

PRINCIPLE The iron is released from ferrioxamine and reduced to the ferrous form by sodium dithionite. It is then separated from urinary pigments by dialysis and reacted with tripyridyl-triazine. The resulting complex, buffered with ammonium acetate, produces a colour which is measured at $600 \mathrm{~m} \mu$.

REDUCING REAGENT Sodium dithionite $(1.5$ g. $)$ is dissolved in $100 \mathrm{ml}$. of iron-free water and the $p \mathrm{H}$ is adjusted rapidly to $7 \cdot 0$ with $2 \mathrm{~N}-\mathrm{NaOH}$. No analytical grade of this reagent is available and general purpose reagent grade is adequate.

BUfFer SOlution Ammonium acetate AR (10 g.) is dissolved in $100 \mathrm{ml}$. of iron-free water and 1 drop of $20 \%$ Tween 20 is added.

COLOUR REAGENT 2, 4, 6-Tripyridyl-triazine AR (10 mg.) is dissolved in $100 \mathrm{ml}$. of $0.05 \mathrm{~N}-\mathrm{HCl}$, and 1 drop of $20 \%$ Tween 20 is added.

Iron-free water is prepared by passing distilled water through a mixed-bed exchange resin.

IRON STANDARD A stock solution (5 mg. of iron per ml.) is prepared by dissolving $4 \cdot 32 \mathrm{~g}$. of ferric ammonium sulphate in $100 \mathrm{ml}$. of $\mathrm{N}-\mathrm{HCl}$. Working standards containing $50,100,200,300,400$, and $500 \mu \mathrm{g}$. iron per $100 \mathrm{ml}$. are prepared from the stock solution by dilution with iron-free water.

Ferrioxamine (Ciba) containing $9 \cdot 130 \mathrm{mg}$. of iron per $100 \mathrm{mg}$. was used.

Received for publication 25 June 1966.
Specimens of urine obtained from normal healthy adults found to contain no iron by prior estimations were used.

AUTOANALYZER ASSEMBLY Using the standard components of an AutoAnalyzer system ${ }^{1}$ the apparatus is set up as described by Young and Hicks (1965). The assembly is set for analysis at a rate of 60 per hour with alternate cups containing iron-free water for an adequate wash. Iron-free water is first run through all lines for 15 minutes. The reagents are then run, with the sample line in iron-free water, for 15 to 30 minutes. A continuous line on the recorder indicates that the system is iron free and the baseline is determined while the reagents are running. Standards up to $500 \mu \mathrm{g}$. iron per $100 \mathrm{ml}$. are run with each batch of urines.

\section{RESULTS}

REPRODUCIBILITY Duplicate estimations of urinary iron were made on 18 specimens to which amounts of ferrioxamine varying from 50 to $500 \mu \mathrm{g} . \%$ had been added. The values obtained for each pair of estimations varied by less than $\pm 1 \cdot 2 \%$.

RECOVERY Recovery experiments were performed by estimating urinary iron after known amounts of ferrioxamine had been added to normal urine and to distilled water. In addition, experiments were performed by adding known amounts of ferric ammonium sulphate to normal urine. For comparison, these experiments were performed on the same samples by the automated method described by Young and Hicks (1965) and by the manual method of Bothwell and Mallett (1955).

Experiment 1 (method of Young and Hicks) Figure 1 shows the recovery of iron from the three test solutions. The recovery from ferric ammonium sulphate added to urine was $100 \%$ at all concentra-

${ }^{1}$ Technicon Instrument Company. 


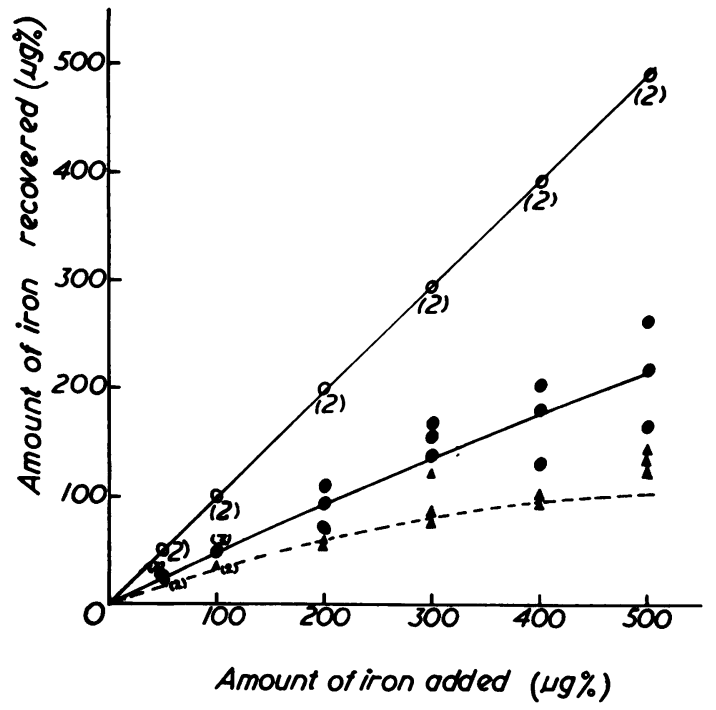

FIG. 1. Recoveries of iron from the test solutions by the automated technique of Young and Hicks (1965). The figures in the parentheses indicate the number of estimations. $\bigcirc-\bigcirc$ represents recoveries from ferric ammonium sulphate added to urine. This corresponds with the theoretical line of $100 \%$ recovery. sents recoveries from ferrioxamine in urine. $\mathbf{\Delta - \Delta}$ represents recoveries from ferrioxamine in water.

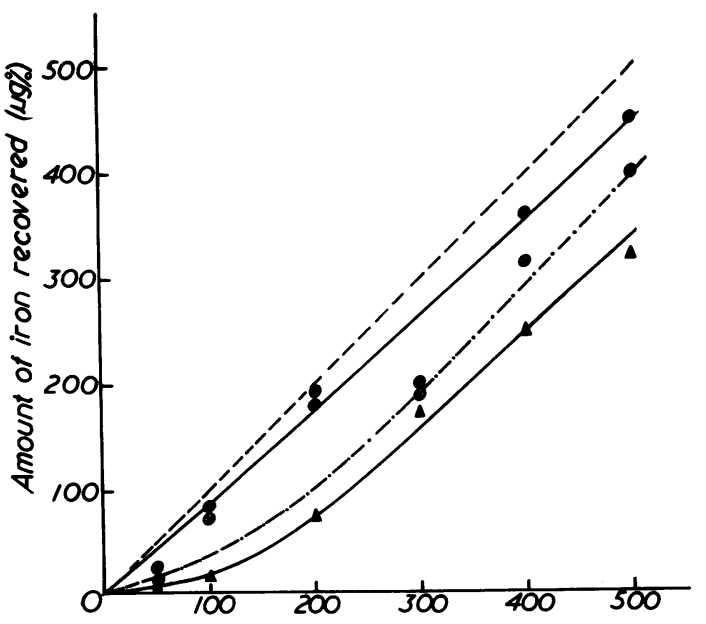

\section{Amount of iron added ( $\mu g \%)$}

FIG. 2. Recovery of iron from the test solutions by the manual method of Bothwell and Mallett (1955). Each point on the graph is the mean of two estimations. Upper broken line indicates the theoretical line of $100 \%$ recovery. - recoveries from ferric ammonium sulphate added to urine. $\otimes-\otimes$ recoveries from ferrioxamine added to urine. $\Delta-\Delta$ recoveries from ferrioxamine added to water. tions. The recovery from ferrioxamine added to urine was $50 \%$ at a concentration of $50 \mu \mathrm{g} . \%$, and it gradually declined to $45 \%$. The recovery from ferrioxamine in water showed a similar decline from $50 \%$ to $20 \%$ as the concentration of iron as ferrioxamine increased from $50 \mu \mathrm{g} . \%$ to $500 \mu \mathrm{g} . \%$.

Experiment 2 (method of Bothwell and Mallett) Figure 2 shows the recovery of iron from the three test solutions. The recovery from ferric ammonium sulphate in urine averaged $90 \%$ of all concentrations and was somewhat lower than that obtained by the method of Young and Hicks. The recovery from ferrioxamine in urine varied from $30 \%$ to $80 \%$ as the concentration increased from $50 \mu \mathrm{g} . \%$ to $500 \mu \mathrm{g} . \%$ of iron.

Experiment 3 (automated technique using sodium dithionite) Figure 3 shows the results of recovery from the three test solutions. The recovery from ferric ammonium sulphate in normal urine was



FIG. 3. Recoveries of iron from the test solutions by the present method. Upper broken line represents the theoretical line of $100 \%$ recovery. $\bigcirc-.-\bigcirc$ represents recoveries from ferric ammonium sulphate added to urine. $\Delta-\Delta$ represents recoveries from ferrioxamine in urine. - represents recoveries from ferrioxamine in water.

$100 \%$ at all concentrations. The recoveries from ferrioxamine in urine and water were identical and ranged from $100 \%$ to $85 \%$ as the concentration increased from $50 \mu \mathrm{g} . \%$ to $500 \mu \mathrm{g} . \%$ of iron.

Figure 4 shows a comparison of the three methods in the recovery of iron from solutions containing ferrioxamine. Recovery was greatest when sodium dithionite was used as the reducing agent. The recovery by the automated technique of Young and 


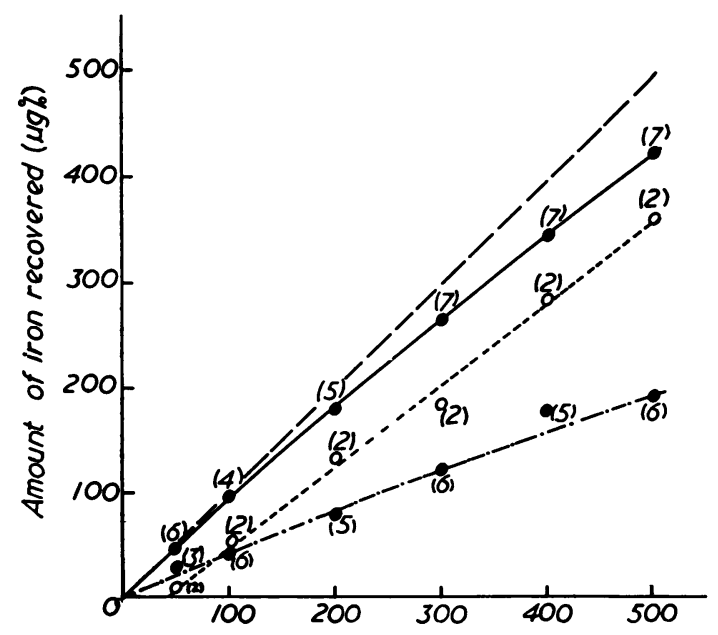

Amount of iron added (ug\%)

FIG. 4. Comparison of recoveries of iron-ferrioxamine containing solutions. Figures in parentheses indicate the number of estimations. Upper broken line indicates the theoretical line of $100 \%$ recovery. - represents the recoveries by the present method. $\bigcirc-.--\bigcirc$ represents the recoveries by the manual method of Bothwell and Mallett. -. - represents the recoveries by the automated method of Young and Hicks.

Hicks (1965) was lowest, ranging from $40 \%$ to $50 \%$ of the added amount. The manual method of Bothwell and Mallett gave an intermediate recovery. As shown in Fig. 4 no iron can be recovered when the concentration of ferrioxamine is equivalent to less than $40 \mu \mathrm{g} . \%$ of iron.

\section{DISCUSSION}

To estimate iron when bound in an organic complex it is necessary to release and reduce it before reaction with tripyridyl-triazine. In the method of Young and Hicks (1965) this is achieved by the use of $0 \cdot 1 \mathrm{~N}$ $\mathrm{HCl}$-ascorbic acid. This is adequate for estimation of protein-bound iron in the serum but is unsuitable in the presence of E.D.T.A. In the present study it has been shown that $\mathrm{HCl}$-ascorbic acid is an unsatisfactory reducing agent for the desferrioxamineiron complex. The recovery of iron from the solutions containing ferrioxamine was $40-50 \%$ at all concentrations of iron (Fig. 4). The use of $2 \mathrm{~N}-\mathrm{HCl}$ as a reducing agent in the manual method of Bothwell and Mallett (1955) gave a higher recovery, but the results of experiments from all the test solutions showed a wider scatter around the mean line (Fig. 2). No iron could be recovered from ferrioxamine at concentrations of less than $40 \mu \mathrm{g} . \%$ of iron (Fig. 4).

When sodium dithionite was used to release iron from the ferrioxamine complex there was complete recovery at a low iron concentration $(50 \mu \mathrm{g} . \%)$, but this declined to $85 \%$ when the concentration was increased to $500 \mu \mathrm{g} . \%$ of iron as ferrioxamine is shown by the $100 \%$ recovery from added ferric ammonium sulphate at all concentrations (Fig. 3).

The method of Bothwell and Mallett (1955) has the additional disadvantage of interference produced by the urinary pigments. This is confirmed by $100 \%$ recovery of added ferric ammonium sulphate by the present technique as well as by the method of Young and Hicks (1965), but a lower recovery from the same solution by the method of Bothwell and Mallett (1955) (Figs. 1, 2, and 3). This difficulty was not overcome by substituting diluted urine for the reagent blank. The use of dialysers in the automated techniques effectively removed the interfering urinary pigments.

Sodium dithionite tends to deposit sulphur in the mixing coils and it was found necessary to limit the concentration to $1.5 \mathrm{~g}$. per $100 \mathrm{ml}$. and to adjust the $p \mathrm{H}$ to 7.0 with $2 \mathrm{~N}-\mathrm{NaOH}$ immediately after the solution was prepared. For the same reason 2, 4, 6-tripyridyl-1, 3, 5-triazine was dissolved in $0.05 \mathrm{~N}$ $\mathrm{HCl}$ rather than $0 \cdot 1 \mathrm{~N}-\mathrm{HCl}$.

The higher yields obtained by the technique reported here may be of significance when assessing the effects of chelation therapy in iron-loaded patients.

This work was carried out during the tenure of a Junior Beit Memorial Fellowship and was also supported by the Endowment Fund of St. Thomas' Hospital.

I am very grateful to Professor G. Wetherley-Mein and Dr. W. J. Griffiths for their help and advice.

\section{REFERENCES}

Bothwell, T. H., and Mallett, B. (1955). Biochem. J., 59, 599. Young, D. S., and Hicks, J. M. (1965). J. clin. Path., 18, 98. 